\title{
Short-term efficacy and safety of MR-guided focused ultrasound surgery for analgesia in children with metastatic bone tumors
}

\author{
BO WANG ${ }^{1}$, JIANNING $\mathrm{LI}^{2}$ and XINHONG WEI ${ }^{3}$ \\ ${ }^{1}$ Department of Ultrasound, Jinan Maternity and Child Care Hospital; ${ }^{2}$ Department of Exceptional Laboratory, \\ Affiliated Hospital of Shandong University of Traditional Chinese Medicine; ${ }^{3}$ Ultrasonic Diagnostic Laboratory, \\ Shandong Medical Imaging Research Institute, Jinan, Shandong 250001, P.R. China
}

Received October 23, 2018; Accepted June 24, 2019

DOI: $10.3892 / \mathrm{ol} .2019 .10628$

\begin{abstract}
Short-term efficacy and safety of magnetic resonance-guided focused ultrasound surgery (MRgFUS) for analgesia in children with metastatic bone tumors were studied. Thirty children with pediatric bone metastases admitted to Jinan Maternity and Child Care Hospital from March 2015 to March 2018 and who received MRgFUS treatment of the bone metastasis lesions were collected. The postoperative efficacy was assessed. The observation indicators included the Numerical Rating Scale (NRS) scores, European Organization for Research and Treatment of Cancer (EORTC) and Quality of Life Questionnaire (QLQ) scores before surgery, and 1 week, 1, 2, and 3 months after surgery and the Karnofsky Performance Status (KPS) scores before surgery, and 1 week and 3 months after surgery. The adverse reactions and medications of the children after the surgery were also under observation. NRS and VAS scores of all different observation time-points after surgery were statistically lower than those before surgery $(\mathrm{P}<0.05)$, and the NRS scores and Visual Analog Scale (VAS) scores 3 months after surgery were lower than those 1 week after surgery $(\mathrm{P}<0.05)$. Compared with the preoperative conditions, the QLQ-C30 scores of terms like physical function, cognitive function, nausea and vomiting, and degree of pain 1 week, 1,2 , and 3 months after surgery were decreased, and the clinical symptoms of the children were relieved $(\mathrm{P}<0.05)$. There was a statistical difference between the total QLQ-C30 scores 3 months after operation and the total QLQ-C30 scores 3 months before operation $(\mathrm{P}<0.05)$. No serious adverse reactions related to treatment were reported, and the application of analgesics was reduced.
\end{abstract}

Correspondence to: Dr Xinhong Wei, Ultrasonic Diagnostic Laboratory, Shandong Medical Imaging Research Institute, 324 Jingwu Road, Jinan, Shandong 250001, P.R. China

E-mail:wgq9he@163.com

Key words: MR-guided focused ultrasound, metastatic bone tumors in children, analgesia, efficacy, safety
MRgFUS relieves bone metastasis pain in children with good curative effect and high safety.

\section{Introduction}

Metastatic bone tumor, a tumor that is metastasized from other parts of the body to the bone through blood or lymphatic pathway (1), occurs in children with malignant tumors $(2,3)$. During the clinical diagnosis and treatment, metastatic bone tumors are often confused with primary bone tumors due to the lack of symptoms of the primary bone tumors (4). The most common malignant tumors in children with bone metastasis are neuroblastoma and nephroblastoma $(5,6)$. Pathological fractures at the metastatic bone often occurs when tumor cells metastasize into the bone, accompanied by severe pain (7), and in some cases, the unbearable pain becomes the main aspect in survival of patients with bone metastases (8). To give safe and effective analgesic treatment in children with bone metastasis has become the top priority in improving the quality of life of children with bone metastases.

High-intensity focused ultrasound (HIFU) [an emerging technology that focuses ultrasound beams emitted from outside the body at target lesions in the body to produce local hyperthermia to kill tumor cells (9)], has been proven by studies to be able to greatly relieve severe pain in patients with advanced pancreatic cancer that cannot be treated surgically (10), and to give good efficacy in the treatment of prostate cancer and breast cancer $(11,12)$. However, the incapability of the HIFU method to perform real-time monitoring on the temperature and the treatment sites brings potential risk that the displaced ultrasound beams and the excessively high temperature may damage the tissues around the lesions and bring other unexpected damage (13). MR-guided focused ultrasound surgery (MRgFUS), with the help of MR imaging technology, can perform temperature monitoring and dynamic localization to guide the ultrasonic scalpel for rapid ablation of target lesions (14), which has achieved good efficacy in treating bone tumors (15). Also, MRgFUS can burn the nerve with focusing heat for the analgesia of severe pain in patients with advanced bone metastasis of malignant tumors (16), thus successfully relieving the pain 
in patients, improving their quality of life and shortening the treatment time. The analgesic effect of MRgFUS on children with metastatic bone tumors was studied and the efficacy and safety evaluated.

\section{Patients and methods}

General information. Thirty children with bone metastases from the Oncology Department of Jinan Maternity and Child Care Hospital (Jinan, China) from March 2015 to March 2018 were collected. There were, 12 children were with neuroblastoma, 7 children with acute leukemia, 6 children with nephroblastoma, and 5 children with lymphoma. Metastatic lesions: 13 cases to ribs, 11 cases to ilium, 4 cases to long bones of the extremities, and 2 cases to sacral vertebrae. There were 20 males and 10 females, aged from 3 to 14 years, with an average age of $4.27 \pm 0.83$ years. Twenty three children were at preschool age and 7 children at school age. Basic information of the patients is shown in Table I. The study was approved by the Ethics Committee of Jinan Maternity and Child Care Hospital. The patients and their guardians were informed, and the informed consent was signed by the parents or guardians.

Inclusion criteria.i) Patients who were confirmed by pathology and imaging examination as bone metastases, aged $\leq 16$ years; ii) bone metastasis target lesions were located in the trunk bones of the extremities, bone joints, pelvis and the posterior part of the spine bone under the fourth lumbar vertebra and were clearly imaged on MRI; and iii) pain sites were fixed, and Numerical Rating Scale (NRS) score (17) $\geq 4$ points, with stable degree of pain and the same type of painkiller 1 week before treatment.

Exclusion criteria. i) Patients who recently received radiotherapy and chemotherapy for target lesions; ii) patients with more than 6 target lesions and an estimated survival time of no more than three months; iii) patients complicated with heart, brain, liver and kidney dysfunction or severe infection; iv) patients who could not be examined by MRI due to built-in metal objects or other reasons; and v) patients who obtained less than 60 points for the Karnofsky Performance Status (KPS) (18) scores.

\section{Experimental methods}

Therapeutic instruments and drugs. Magnetic resonance imaging system (Shanghai Ge Medical Instrument Co., Ltd., 3460244); MRgFUS (Exablate 2100; InSightec, Ltd.); Gd-DTPA (MR-00P10; Shanghai Sunr Biotech Co., Ltd.); ketamine hydrochloride injection (H32022820; Jiangsu Hengrui Medicine Co., Ltd.); atropine sulfate injection (H41021272; Jiaozuo Furuitang Pharmaceutical Co., Ltd.).

Treatment methods. After finishing all routine clinical examinations and completing the basic information, all patients were required to perform the preoperative preparations such as fasting and water deprivation for $6 \mathrm{~h}$ before surgery, preoperative hair removal, to establish venous access and indwell the catheter. To reduce movement, patients were given intramuscular injection of sedative
Table I. General clinical data (mean \pm SD) [n (\%)].

\begin{tabular}{|c|c|}
\hline $\begin{array}{l}\text { Clinical } \\
\text { factors }\end{array}$ & $\begin{array}{l}\text { Number of } \\
\text { the case }(\%)\end{array}$ \\
\hline \multicolumn{2}{|l|}{ Sex } \\
\hline Male & $20(66.67)$ \\
\hline Female & $10(33.33)$ \\
\hline \multicolumn{2}{|l|}{ Age } \\
\hline$\leq 7$ & $23(76.67)$ \\
\hline$>7$ & $7(23.33)$ \\
\hline Weight & $18.73 \pm 10.34$ \\
\hline Height & $98.24 \pm 8.83$ \\
\hline \multicolumn{2}{|l|}{ Primary tumors } \\
\hline Neuroblastoma & $12(40.00)$ \\
\hline Acute leukemia & $7(23.33)$ \\
\hline Nephroblastoma & $6(20.00)$ \\
\hline Lymphoma & $5(16.67)$ \\
\hline Other diseases & $2(6.67)$ \\
\hline \multicolumn{2}{|l|}{$\begin{array}{l}\text { Received treatments } 3 \text { months } \\
\text { before the surgery }\end{array}$} \\
\hline Radiotherapy & $9(30.00)$ \\
\hline Chemotherapy & $11(36.67)$ \\
\hline Operation & $6(20.00)$ \\
\hline Other treatments & $4(13.33)$ \\
\hline \multicolumn{2}{|l|}{ Location of lesions } \\
\hline Rib & $13(43.33)$ \\
\hline Ilium & $11(36.67)$ \\
\hline Long bone of limbs & $4(13.33)$ \\
\hline Sacral vertebrae & $2(6.67)$ \\
\hline \multicolumn{2}{|l|}{ Nature of the lesions } \\
\hline Osteoblastic & $14(46.67)$ \\
\hline Osteolytic & $5(16.67)$ \\
\hline Mixed type & $11(36.67)$ \\
\hline \multicolumn{2}{|l|}{ Size of the lesions } \\
\hline Anteroposterior diameter $/ \mathrm{mm}$ & $13.49 \pm 8.34$ \\
\hline Transverse diameter/mm & $23.37 \pm 10.47$ \\
\hline Vertical diameter/mm & $25.62 \pm 9.35$ \\
\hline Volume/ml & $932.45 \pm 6,142.36$ \\
\hline
\end{tabular}

(ketamine, $0.5 \mathrm{mg} / \mathrm{kg}$ + atropine $0.02 \mathrm{mg} / \mathrm{kg}$ ), then they were escorted to the operating room by the anesthesiologist and family members $10 \mathrm{~min}$ after the injection when the blood concentration reached its peak. The treatment bed was adjusted according to the location of the specific target lesion so that the ultrasonic scalpel beam could directly reach the painful part of the target lesion, and a soft pad was used for fixing the position of patients to make the long axis of the bone where the target lesions were located parallel to the treatment axis. Real-time electrocardiographic monitoring was performed together with artificial monitoring by the anesthesiologist who closely checked the patient's complexion and the chest expansion and stopped the treatment if any abnormality occurred. Fat-suppression T1W1 and T2W1 
Table II. Score of the analgesia efficacy after surgery (mean \pm SD).

\begin{tabular}{|c|c|c|c|c|c|c|c|}
\hline \multirow[b]{2}{*}{ Score } & \multirow{2}{*}{$\begin{array}{l}\text { Before } \\
\text { surgery }\end{array}$} & \multicolumn{4}{|c|}{ After surgery } & \multirow[b]{2}{*}{ F-value } & \multirow[b]{2}{*}{ P-value } \\
\hline & & 1 week & 1 month & 2 months & 3 months & & \\
\hline NRS & $6.27 \pm 1.53$ & $3.69 \pm 1.71^{\mathrm{a}}$ & $3.13 \pm 1.87^{\mathrm{a}}$ & $2.76 \pm 1.53^{\mathrm{a}}$ & $2.18 \pm 1.04^{\mathrm{a}, \mathrm{b}}$ & 31.020 & $<0.001$ \\
\hline VAS & $6.56 \pm 2.38$ & $4.72 \pm 2.34^{\mathrm{a}}$ & $3.43 \pm 2.16^{\mathrm{a}}$ & $2.29 \pm 1.15^{\mathrm{a}, \mathrm{b}}$ & $1.85 \pm 0.96^{\mathrm{a}-\mathrm{c}}$ & 30.880 & $<0.001$ \\
\hline
\end{tabular}

${ }^{\mathrm{a}} \mathrm{P}<0.05$, when compared with NRS and VAS scores before surgery; ${ }^{\mathrm{P}} \mathrm{P}<0.05$, when compared with NRS and VAS scores 1 week after surgery; ${ }^{\mathrm{c}} \mathrm{P}<0.05$, when compared with NRS and VAS scores 1 month after surgery. NRS, numerical rating scale; VAS, visual analog scale; SD, standard deviation.

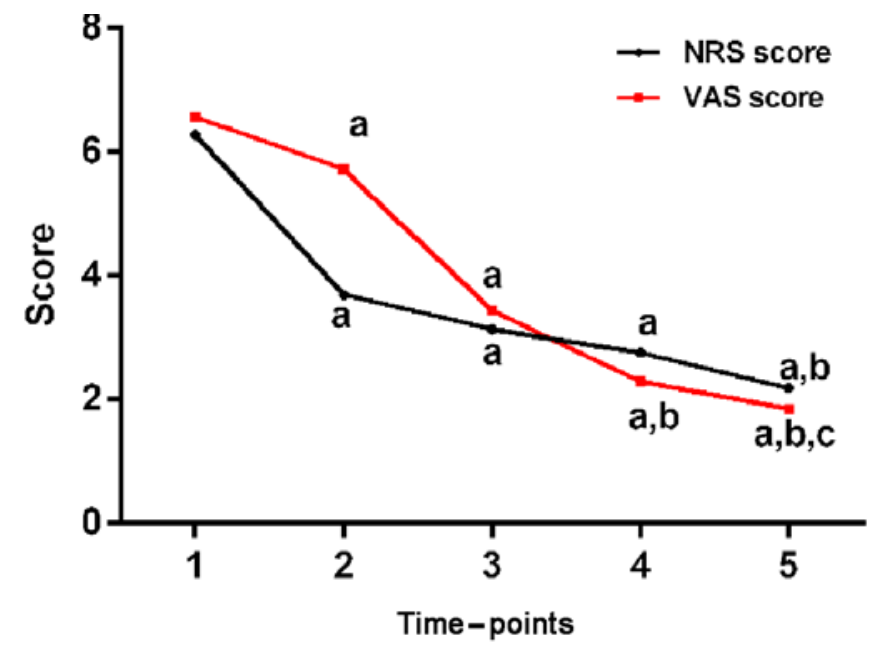

Figure 1. Score of the analgesia efficacy after MRgFUS. NRS and VAS scores of all different observation time-points after surgery were statistically lower than those before surgery $(\mathrm{P}<0.05)$, and NRS and VAS scores 3 months after surgery were lower than those 1 week after surgery $(\mathrm{P}<0.05)$. The analgesic effect was relatively sustained. ${ }^{a} \mathrm{P}<0.05$, when compared with the NRS and VAS scores before surgery; ${ }^{\mathrm{b}} \mathrm{P}<0.05$, when compared with the NRS and VAS scores 1 week after surgery; ${ }^{c} \mathrm{P}<0.05$, when compared with the NRS and VAS scores 1 month after surgery. MRgFUS, magnetic resonance-guided focused ultrasound surgery; NRS, Numerical Rating Scale; VAS, visual analog scale.

scans were performed on the sagittal and cross sections of the target lesion before treatment (the layer thickness was 4-7 mm, spacing $1 \mathrm{~mm}$ per layer. Gd-DTPA was injected through the cubital vein during the enhanced scan, $0.15 \mathrm{ml} / \mathrm{kg}$ ). The contour of the target lesion area and the protective area of the key structure were manually outlined on the fat-suppression T2W1 image on the cross-section and then entered into the MRgFUS system to make relevant treatment plan with the help of artificial adjustment on the actual number of target lesions and the energy required by the target lesions. The focus of the ultrasonic beam was continuously moved, and the temperature of the target lesion area was maintained at $60-85^{\circ} \mathrm{C}$ for $20-30 \mathrm{sec}$ each time. The MRI imaging system was used during the whole process of treatment to monitor the real-time temperature and shape of target lesions and their surrounding area.

Observation indicators. NRS score, visual analog scale (VAS) (19), and European Organization for Research and Treatment of Cancer (EORTC) Quality of Life Questionnaire
(QLQ) score (20) before surgery and 1 week, 1, 2, and 3 months after surgery, as well as the KPS scores before surgery and 1 week, 1 and 3 months after surgery were used to assess the analgesic efficacy of the children. Among them, the items of the QLQ-C30 scores were classified as 'completely absent, mild, severe and deeply severe', with a score of 1 to 4 points. The analgesic drugs before and after treatment were recorded, and the adverse reactions such as treatment-related pathological fractures, regional tissue edema, and abnormal feelings in the treatment area were closely observed.

Statistical analysis. Experimental data were statistically analyzed using SPSS software 19.0 (SPSS Inc.). Measurement data were expressed as (mean $\pm \mathrm{SD}$ ), enumeration data were expressed as cases (percentage) [n (\%)]. Repeated measures ANOVA was used to compare the data of multiple time-points, and the Bonferroni test was used for comparison between two different points in the group. Statistical significance was recognized at $\mathrm{P}<0.05$.

\section{Results}

Treatment outcome. MRgFUS treatment was successfully completed in 30 children with metastatic bone tumors, with an operation time of $123 \pm 21 \mathrm{~min}$ per patient. The average ultrasound pulse for each target lesion was $13 \pm 8$ times. Eight of the 30 children with metastatic bone tumors received a second treatment over 3 weeks after the first treatment. All patients underwent a 3-month follow-up.

Score of the analgesia efficacy after surgery. NRS scores and VAS scores of all different observation time-points after surgery were statistically lower than those before surgery $(\mathrm{P}<0.05)$, and the NRS and VAS scores 3 months after surgery were lower than those 1 week after surgery $(\mathrm{P}<0.05)$. The analgesic effect was relatively sustained. The specific data are shown in Table II and Fig. 1.

QLQ-C30 scores before and after treatment. Compared with the preoperative conditions, QLQ-C30 scores of physical function, cognitive function, nausea and vomiting, and degree of pain 1 week, 1, 2, and 3 months after surgery were decreased, and the clinical symptoms of the children were relieved $(\mathrm{P}<0.05)$. There was a statistical difference between total QLQ-C30 scores 3 months after operation and total QLQ-C30 
Table III. QLQ-C30 scores before and after the treatment of the patients (mean \pm SD).

\begin{tabular}{|c|c|c|c|c|c|c|c|}
\hline Time & $\begin{array}{l}\text { Total } \\
\text { score }\end{array}$ & $\begin{array}{l}\text { Physical } \\
\text { function }\end{array}$ & $\begin{array}{l}\text { Cognitive } \\
\text { function }\end{array}$ & $\begin{array}{l}\text { Nausea and } \\
\text { vomiting }\end{array}$ & $\begin{array}{l}\text { Degree } \\
\text { of pain }\end{array}$ & Astriction & Diarrhea \\
\hline Before surgery & $16.98 \pm 5.38$ & $2.52 \pm 0.64$ & $2.26 \pm 0.42$ & $1.87 \pm 0.62$ & $7.32 \pm 2.45$ & $1.73 \pm 0.78$ & $1.28 \pm 0.47$ \\
\hline \multicolumn{8}{|l|}{ After surgery } \\
\hline 1 week & $13.26 \pm 3.89^{a}$ & $2.07 \pm 0.68^{\mathrm{a}}$ & $1.78 \pm 0.58^{a}$ & $1.54 \pm 0.52^{\mathrm{a}}$ & $5.37 \pm 1.56^{\mathrm{a}}$ & $1.41 \pm 0.32^{\mathrm{a}}$ & $1.09 \pm 0.23^{\mathrm{a}}$ \\
\hline 1 month & $12.44 \pm 3.20^{\mathrm{a}}$ & $1.94 \pm 0.68^{\mathrm{a}}$ & $1.56 \pm 0.35^{\mathrm{a}}$ & $1.43 \pm 0.33^{\mathrm{a}}$ & $5.13 \pm 1.45^{\mathrm{a}}$ & $1.36 \pm 0.28^{\mathrm{a}}$ & $1.02 \pm 0.11^{\mathrm{a}}$ \\
\hline 2 months & $10.80 \pm 3.44^{\mathrm{a}-\mathrm{c}}$ & $1.41 \pm 0.72^{\mathrm{a}-\mathrm{c}}$ & $1.36 \pm 0.47^{\mathrm{a}, \mathrm{b}}$ & $1.23 \pm 0.32^{\mathrm{a}}$ & $4.74 \pm 1.36^{\mathrm{a}}$ & $1.14 \pm 0.37^{\mathrm{a}}$ & $0.92 \pm 0.20^{\mathrm{a}}$ \\
\hline 3 months & $9.70 \pm 2.98^{a-c}$ & $1.27 \pm 0.36^{\mathrm{a}-\mathrm{c}}$ & $1.14 \pm 0.63^{\mathrm{a}-\mathrm{c}}$ & $1.15 \pm 0.34^{\mathrm{a}, \mathrm{b}}$ & $4.37 \pm 1.26^{\mathrm{a}}$ & $1.04 \pm 0.25^{\mathrm{a}-\mathrm{c}}$ & $0.73 \pm 0.14^{\mathrm{a}-\mathrm{d}}$ \\
\hline F-value & 93.830 & 19.580 & 22.050 & 12.340 & 14.100 & 10.900 & 18.000 \\
\hline P-value & $<0.001$ & $<0.001$ & $<0.001$ & $<0.001$ & $<0.001$ & $<0.001$ & $<0.001$ \\
\hline
\end{tabular}

${ }^{\mathrm{a}} \mathrm{P}<0.05$, when compared with QLQ-C30 scores before surgery; ${ }^{\mathrm{b}} \mathrm{P}<0.05$, when compared with QLQ-C30 scores 1 week after surgery; ${ }^{\mathrm{C}}<0.05$, when compared with QLQ-C30 scores 1 month after surgery; ${ }^{\mathrm{d}} \mathrm{P}<0.05$, when compared with QLQ-C30 scores 2 months after surgery.

Table IV. KPS scores before and after the treatment of the patients (mean \pm SD).

\begin{tabular}{|c|c|c|c|c|c|}
\hline \multirow[b]{2}{*}{ Score } & \multirow[b]{2}{*}{ Before treatment } & \multicolumn{2}{|c|}{ After treatment } & \multirow[b]{2}{*}{ F-value } & \multirow[b]{2}{*}{ P-value } \\
\hline & & 1 week & 3 months & & \\
\hline KPS & $86.37 \pm 7.19$ & $84.78 \pm 7.38$ & $83.15 \pm 7.86$ & 1.389 & 0.255 \\
\hline
\end{tabular}

KPS, Karnofsky Performance Status; SD, standard deviation.

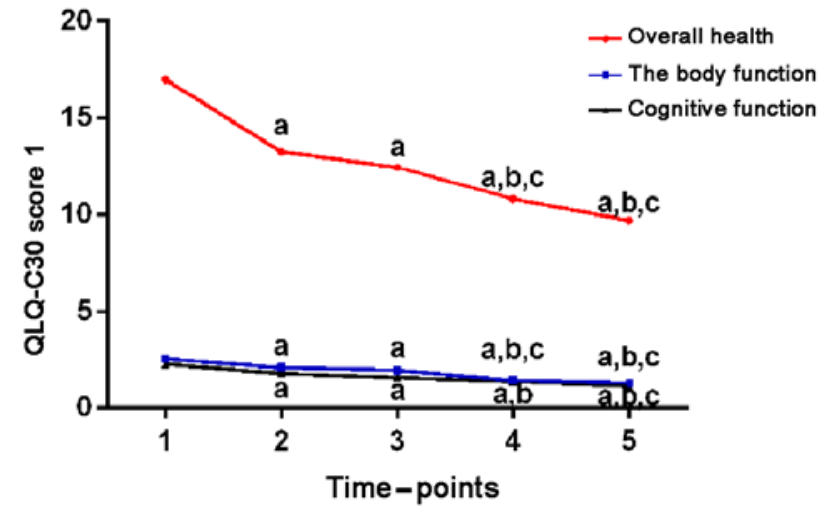

Figure 2. QLQ-C30 scores before and after treatment (1). Compared with the preoperative conditions, QLQ-C30 scores such as physical function, cognitive function and total QLQ-C30 scores 1 week, 1, 2, and 3 months after surgery were statistically lower than those before surgery $(\mathrm{P}<0.05)$. ${ }^{\mathrm{a}} \mathrm{P}<0.05$, when compared with QLQ-C30 scores before surgery; ${ }^{\mathrm{b}} \mathrm{P}<0.05$, when compared with QLQ-C30 scores 1 week after surgery; ${ }^{\mathrm{P}}<0.05$, when compared with QLQ-C30 scores 1 month after surgery. QLQ, Quality of Life Questionnaire.

scores before operation $(\mathrm{P}<0.05)$. The specific data are shown in Table III, Figs. 2 and 3.

KPS scores before and after treatment in patients. As shown in Table IV, the KPS scores of children with metastatic tumors of all different observation time-points after surgery were slightly lower than those before surgery, but the difference was not statistically significant $(\mathrm{P}>0.05)$, indicating that the

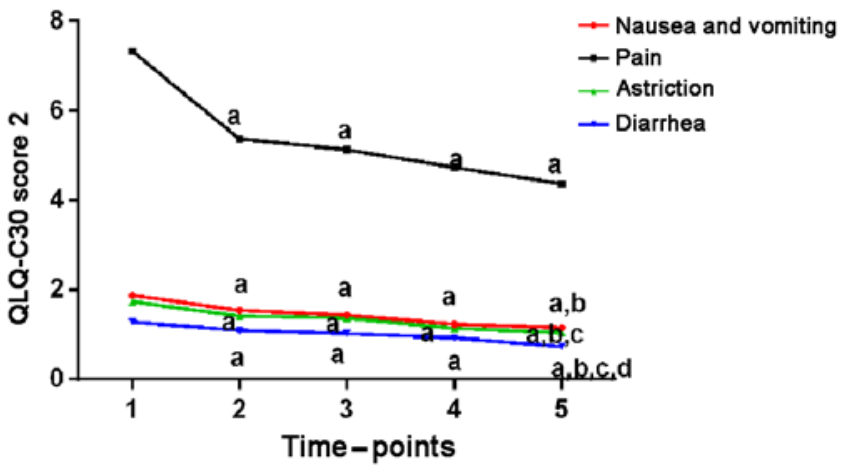

Figure 3. QLQ-C30 scores before and after treatment (2). Compared with the preoperative conditions, QLQ-C30 scores such as nausea, vomiting, feeling painful, constipation, and diarrhea 1 week, 1, 2, and 3 months after surgery were lower, and clinical symptoms of children were all relieved to different extent $(\mathrm{P}<0.05)$. ${ }^{\mathrm{a}} \mathrm{P}<0.05$, when compared with $\mathrm{QLQ}-\mathrm{C} 30$ scores before surgery; ${ }^{\mathrm{b}} \mathrm{P}<0.05$, when compared with QLQ-C30 scores 1 week after surgery; ${ }^{\mathrm{C}}<0.05$, when compared with QLQ-C30 scores 1 month after surgery; ${ }^{\mathrm{d}} \mathrm{P}<0.05$, when compared with QLQ-C30 scores 2 months after surgery. QLQ, Quality of Life Questionnaire.

patients' condition was stable during the treatment period without deterioration.

Medication. Thirteen patients took fixed analgesics with stable dosage before surgery, among whom six patients stopped taking drug after treatment, 4 patients stopped taking drug 2 months after surgery, 2 patients reduced the dosage of analgesics after surgery and 1 patient took the same dosage 
as that before surgery. The other 17 patients had no analgesic medication before operation, among whom only 1 patient was in need for analgesics due to failed analgesic effect on unbearable pain, 2 patients had to take analgesics 3 months after surgery because of the pain aroused by metastatic bone tumor at other sites, and the other 14 patients still did not required any analgesics after surgery.

Adverse reactions. During the treatment of the 30 children with metastatic bone tumors, 2 patients had I degree burns which were relieved 3 days after symptomatic treatment; 3 patients were troubled by local swelling and numbness in the treatment area which was caused by compression of peripheral nerves due to local swelling according to the MRI examination, and felt better after symptomatic treatment. After the treatment 3 patients suffered from low fever which disappeared within 1 month after surgery. No serious complications such as deep vein thrombosis of the lower limbs or death of patients occurred during the treatment.

\section{Discussion}

As a group of diseases with high risk among various pediatric diseases, malignant tumors in children are characterized by fast condition change, since children are growing (21), and many tumors at their early stage are hard to diagnose due to children's poor ability to express feelings and the inapparent early symptoms (22), contributing to the easily occurring metastasis of advanced tumors among which the bone metastasis is one of the most common ones (23). The pain of bone and joint caused by bone metastases of malignant tumors is often an important factor in damaging patients' physical and mental health (24), causing great suffering to children and their families (25).

Analgesic drugs combined with chemotherapy, often applied in the treatment of advanced malignant tumors after bone metastasis, bring great toxic side effects on children and cause much damage to the growth and development of children, and the abuse of painkillers can easily lead to addiction (26,27). Currently MRgFUS has achieved good results in the analgesic of metastatic bone tumors in adults (28) as the targeted therapy of MRgFUS on local target lesions performed by the thermal ablation technique can achieve satisfactory analgesia by burning nerve endings attached to the periosteum around the target lesions and killing tumor cells at the same time (29). Despite the safety and good efficacy of this MRgFUS technology, it is seldom applied to the treatment of metastatic bone tumors in children, so this study was designed to investigate the analgesic effect and safety of MRgFUS in children with metastatic bone tumors.

According to the results of this study, the NRS score and VAS score of the children at different time-points after surgery were significantly lower than those before surgery. The application of analgesics was reduced in most children, suggesting that the MRgFUS treatment could effectively relieve the pain in children aroused by metastatic bone tumors, working as a substitute for some analgesics. The study of Joo et al (30) showed that the NRS score could even be reduced from 7 to 0.3 on children with metastatic bone tumors one year after the MRgFUS treatment. However, the present study focused on the short-term efficacy of MRgFUS, and performed a double evaluation of the NRS and the VAS score, and showed that the MRgFUS treatment could also achieve good analgesic effect on children with metastatic bone tumors, since the pain of children in this study was relieved after treatment. Compared with the preoperative conditions, the QLQ-C30 scores of physical function, cognitive function, nausea and vomiting, and degree of pain 1 week, 1, 2 and 3 months after surgery were decreased, and the clinical symptoms of children were relieved at different degrees. There was a statistical difference between the total QLQ-C30 scores 3 months after operation and the total QLQ-C30 scores before operation, showing good improvement in life treatment and clinical symptoms and sustained efficacy in children with metastatic bone tumors after the MRgFUS treatment. Gu et al (31) found that the EORTC QLQ score after MRgFUS treatment was significantly decreased, and the quality of life of patients was significantly improved, which is consistent with the results of our study. In addition, we conducted a more specific analysis and comparison of the quality of life and clinical symptoms of children with metastatic bone tumors in multiple aspects and multiple periods, providing a more convincing result that the MRgFUS treatment may achieve good and continuous efficacy in children with metastatic bone tumors. The KPS scores of children with metastatic tumors of all different observation time-points after surgery were slightly lower than those before surgery, but the difference was not statistically significant. Previous studies have shown that poor KPS scores may be the prognostic risk factors of many malignant tumors $(32,33)$. During the treatment, the KPS score was relatively stable, and the children did not have serious adverse reactions related to treatment, indicating that the treatment of MRgFUS in children with metastatic bone tumors had good safety. As to the 2 cases of I degree burns during the treatment, a possible reason was the temperature of the thermal ablation which was relatively too high to children with more delicate skin than adults. After taking this into consideration in the later stage of the experiment, no other reports of burning occurred.

However, there are some limitations in this study. The children were generally too young, so most of the evaluation of the analgesic efficacy scores was assisted by the family members of the children, which might have some impacts on the results of the study. No control group was set up due to the limited experimental conditions. The sample size was small in this study. Multi-center and multi-regional samples need to be included, and the study period needs to be extended in future studies.

In summary, the MRgFUS technology is worthy of further research since it was proved to achieve a good analgesic effect on children with metastatic bone tumors, and to improve the quality of life and clinical symptoms to a certain extent, with fewer adverse reactions and higher safety.

\section{Acknowledgements}

Not applicable.

\section{Funding}

No funding was received. 


\section{Availability of data and materials}

The datasets used and/or analyzed during the current study are available from the corresponding author on reasonable request.

\section{Authors' contributions}

BW was responsible for the writing of the manuscript and treatment of patients. JL and XW analyzed observation indicators and revised the manuscript. All the authors read and approved the final manuscript.

\section{Ethics approval and consent to participate}

This study was approved by the Ethics Committee of Jinan Maternity and Child Care Hospital (Jinan, China). Patients who participated in this research had complete clinical data. The signed informed consents were obtained from the parents of the child patients or the guardians.

\section{Patient consent for publication}

Not applicable.

\section{Competing interests}

The authors declare that they have no competing interests.

\section{References}

1. Krzeszinski JY and Wan Y: New therapeutic targets for cancer bone metastasis. Trends Pharmacol Sci 36: 360-373, 2015.

2. Drubach LA: Nuclear medicine techniques in pediatric bone imaging. Semin Nucl Med 47: 190-203, 2017.

3. Yi JL, Galgano MA, Tovar-Spinoza Z and Deshaies EM: Coil embolization of an intracranial aneurysm in an infant with tuberous sclerosis complex: A case report and literature review. Surg Neurol Int 3: 129, 2012.

4. Reufsteck C, Lifshitz-Shovali R, Zepp M, Bäuerle T, Kübler D, Golomb G and Berger MR: Silencing of skeletal metastasis-associated genes impairs migration of breast cancer cells and reduces osteolytic bone lesions. Clin Exp Metastasis 29: 441-456, 2012.

5. Ishiguchi H, Ito S, Kato K, Sakurai Y, Kawai H, Fujita N, Abe S, Narita A, Nishio N, Muramatsu H, et al: Diagnostic performance of 18F-FDG PET/CT and whole-body diffusion-weighted imaging with background body suppression (DWIBS) in detection of lymph node and bone metastases from pediatric neuroblastoma. Ann Nucl Med 32: 348-362, 2018.

6. Chung EM, Graeber AR and Conran RM: Renal tumors of childhood: Radiologic-pathologic correlation Part 1. The 1st decade: From the radiologic pathology archives. Radiographics 36: 499-522, 2016.

7. Kim LD, Bueno FT, Yonamine ES, Próspero JD and Pozzan G: Bone metastasis as the first symptom of tumors: Role of an immunohistochemistry study in establishing primary tumor. Rev Bras Ortop 53: 467-471, 2018.

8. von Moos R, Body JJ, Egerdie B, Stopeck A, Brown J, Fallowfield L, Patrick DL, Cleeland C, Damyanov D, Palazzo FS, et al: Pain and analgesic use associated with skeletal-related events in patients with advanced cancer and bone metastases. Support Care Cancer 24: 1327-1337, 2016.

9. Trimboli P, Bini F, Marinozzi F, Baek JH and Giovanella L: High-intensity focused ultrasound (HIFU) therapy for benign thyroid nodules without anesthesia or sedation. Endocrine 61: 210-215, 2018.

10. Marinova M, Strunk HM, Rauch M, Henseler J, Clarens T, Brüx L, Dolscheid-Pommerich R, Conrad R, Cuhls H, Radbruch L, et al: High-intensity focused ultrasound (HIFU) for tumor pain relief in inoperable pancreatic cancer: Evaluation with the pain sensation scale (SES). Schmerz 31: 31-39, 2017 (In German).
11. Ganzer R: High intensity focused ultrasound (HIFU): Importance in the treatment of prostate cancer. Radiologe 57: 659-664, 2017 (In German).

12. Merckel LG, Knuttel FM, Deckers R, van Dalen T, Schubert G, Peters NH, Weits T, van Diest PJ, Mali WP, Vaessen PH, et al: First clinical experience with a dedicated MRI-guided high-intensity focused ultrasound system for breast cancer ablation. Eur Radiol 26: 4037-4046, 2016.

13. Sanghvi NT, Chen WH, Carlson R, Weis C, Seip R, Uchida T and Marberger M: Clinical validation of real-time tissue change monitoring during prostate tissue ablation with high intensity focused ultrasound. J Ther Ultrasound 5: 24, 2017.

14. Salomir R, Vimeux FC, de Zwart JA, Grenier N and Moonen CT: Hyperthermia by MR-guided focused ultrasound: Accurate temperature control based on fast MRI and a physical model of local energy deposition and heat conduction. Magn Reson Med 43: 342-347, 2000.

15. Ringe KI, Panzica M and von Falck C: Thermoablation of bone tumors. RoFo 188: 539-550, 2016.

16. Hurwitz MD, Ghanouni P, Kanaev SV, Iozeffi D, Gianfelice D, Fennessy FM, Kuten A, Meyer JE, LeBlang SD, Roberts A, et al: Magnetic resonance-guided focused ultrasound for patients with painful bone metastases: Phase III trial results. J Natl Cancer Inst 106: 106, 2014.

17. Løhre ET, Klepstad P, Bennett MI, Brunelli C, Caraceni A, Fainsinger RL, Knudsen AK, Mercadante S, Sjøgren P and Kaasa S; European association for palliative care research network: From 'Breakthrough' to 'Episodic' cancer pain? A European association for palliative care research network expert Delphi survey toward a common terminology and classification of transient cancer pain exacerbations. J Pain Symptom Manage 51: 1013-1019, 2016

18. Chambless LB, Kistka HM, Parker SL, Hassam-Malani L, McGirt MJ and Thompson RC: The relative value of postoperative versus preoperative Karnofsky Performance Scale scores as a predictor of survival after surgical resection of glioblastoma multiforme. J Neurooncol 121: 359-364, 2015.

19. Lee JJ, Lee MK, Kim JE, Kim HZ, Park SH, Tae JH and Choi SS: Pain relief scale is more highly correlated with numerical rating scale than with visual analogue scale in chronic pain patients. Pain Physician 18: E195-E200, 2015.

20. Raman S, Ding K, Chow E, Meyer RM, van der Linden YM, Roos D, Hartsell WF, Hoskin P, Wu JSY, Nabid A, et al: Minimal clinically important differences in the EORTC QLQ-C30 and brief pain inventory in patients undergoing re-irradiation for painful bone metastases. Qual Life Res 27: 1089-1098, 2018.

21. Lozier AM, Rich ME, Grawe AP, Peck AS, Zhao P, Chang ATT, Bond JP and Sholler GS: Targeting ornithine decarboxylase reverses the LIN28/Let-7 axis and inhibits glycolytic metabolism in neuroblastoma. Oncotarget 6: 196-206, 2015.

22. Merchant TE, Hua CH, Shukla H, Ying X, Nill S and Oelfke U: Proton versus photon radiotherapy for common pediatric brain tumors: Comparison of models of dose characteristics and their relationship to cognitive function. Pediatr Blood Cancer 51: 110-117, 2008.

23. Zhang X, Li C, Xu C, Hao X, Yu X and Li Q: Correlation of CT signs with lymphatic metastasis and pathology of neuroblastoma in children. Oncol Lett 16: 2439-2443, 2018.

24. Wu Z, Yang H, Weng D and Ding Y: Rapid recurrence and bilateral lungs, multiple bone metastasis of malignant solitary fibrous tumor of the right occipital lobe: Report of a case and review. Diagn Pathol 10: 91, 2015.

25. Olagunju AT, Sarimiye FO, Olagunju TO, Habeebu MY and Aina OF: Child's symptom burden and depressive symptoms among caregivers of children with cancers: An argument for early integration of pediatric palliative care. Ann Palliat Med 5: 157-165, 2016.

26. Moroe NF and Hughes K: Parents are aware of the ototoxic effects of chemotherapy in paediatrics undergoing cancer treatment - Professional versus parental views: A pilot study. S Afr J Commun Disord 64: e1-e10, 2017.

27. Zelikowsky M and Fanselow MS: Opioid regulation of Pavlovian overshadowing in fear conditioning. Behav Neurosci 124: 510-519, 2010.

28. Catane R, Beck A, Inbar Y, Rabin T, Shabshin N, Hengst S, Pfeffer RM, Hanannel A, Dogadkin O, Liberman B, et al: MR-guided focused ultrasound surgery (MRgFUS) for the palliation of pain in patients with bone metastases - preliminary clinical experience. Ann Oncol 18: 163-167, 2007. 
29. Dababou S, Marrocchio C, Scipione R, Erasmus HP, Ghanouni P, Anzidei M, Catalano C and Napoli A: High-intensity focused ultrasound for pain management in patients with cancer. Radiographics 38: 603-623, 2018.

30. Joo B, Park MS, Lee SH, Choi HJ, Lim ST, Rha SY, Rachmilevitch I, Lee YH and Suh JS: Pain palliation in patients with bone metastases using magnetic resonance-guided focused ultrasound with conformal bone system: A preliminary report. Yonsei Med J 56: 503-509, 2015.

31. Gu J, Wang H, Tang N, Hua Y, Yang H, Qiu Y, Ge R, Zhou Y, Wang W and Zhang G: Magnetic resonance guided focused ultrasound surgery for pain palliation of bone metastases: Early experience of clinical application in China. Zhonghua Yi Xue Za Zhi 95: 3328-3332, 2015 (In Chinese)
32. Geng M, Xu H, Ren R, Qu Q, Shangguan C, Wu J, Jiang J, Li H and Cao W: Prognostic value of clinicopathological characteristics in patients with pancreatic cancer. Chin J Cancer Res 27: 509-515, 2015

33. Ventriglia J, Petrillo A, Huerta Alváro M, Laterza MM, Savastano B, Gambardella V, Tirino G, Pompella L, Diana A, Iovino F, et al: Neutrophil to lymphocyte ratio as a predictor of poor prognosis in metastatic pancreatic cancer patients treated with Nab-Paclitaxel Plus Gemcitabine: A propensity score analysis. Gastroenterol Res Pract 2018: 2373868, 2018.

(i) (9) This work is licensed under a Creative Commons Attribution-NonCommercial-NoDerivatives 4.0 International (CC BY-NC-ND 4.0) License. 